\title{
BMJ Open Effect of self-reported home smoking restriction on smoking initiation among adolescents in Taiwan: a prospective cohort study
}

\author{
Dih-Ling Luh, ${ }^{1,2}$ Hsiu-Hsi Chen, ${ }^{3}$ Amy Ming-Fang Yen, ${ }^{4}$ Ting-Ting Wang, ${ }^{4}$ \\ Sherry Yueh-Hsia Chiu, ${ }^{5}$ Ching-Yuan Fann, ${ }^{6}$ Sam Li-Sheng Chen ${ }^{4}$
}

To cite: Luh D-L, Chen $\mathrm{H}-\mathrm{H}$ Yen AM-F, et al. Effect of self-reported home smoking restriction on smoking initiation among adolescents in Taiwan: a prospective cohort study. BMJ Open 2015;5:e007025. doi:10.1136/bmjopen-2014007025

- Prepublication history for this paper is available online. To view these files please visit the journal online (http://dx.doi.org/10.1136/ bmjopen-2014-007025).

Received 29 October 2014 Revised 12 March 2015 Accepted 20 March 2015

CrossMark

For numbered affiliations see end of article.

Correspondence to

Dih-Ling Luh;

luh@csmu.edu.tw

\section{ABSTRACT}

Objective: The aims of this study were to investigate the influence of home smoking restriction (HSR) and the modified effect of parental smoking on smoking initiation among adolescents.

Design: Prospective Cohort Study.

Setting: Junior high school in Keelung City, Taiwan.

Participants: This study collected and evaluated primary data from the Adolescent Smoking and Other Health-Related Behaviour Survey conducted in Keelung City, which aimed to investigate smoking and healthrelated behaviours in junior high school students (2008-2009). Data on students free of smoking in 2008 and following them until $2009(n=901)$ to ascertain whether they had started smoking were analysed with logistic regression mode to examine the proposed postulates.

Main outcome measure: The outcome variable was smoking initiation, which was defined as smoking status (yes/no) in the 2009 follow-up questionnaire. The main independent variable was HSR obtained from an adolescent self-reported questionnaire. Information on parental smoking was measured by adolescents selfreporting the smoking behaviour of their father and mother.

Results: The rate of HSR was $29.79 \%$ among 7 th grade adolescents. The effect of HSR on smoking initiation in adolescents was statistically significantly modified by paternal smoking $(\mathrm{p}=0.04)$ but not by maternal smoking $(p=0.54)$. The effect of HSR on smoking initiation was small for fathers with the habit of smoking ( $O R=0.89$, $95 \% \mathrm{Cl}(0.42$ to 1.88$))$, but the corresponding effect size was 3.2-fold (OR=2.84, $95 \% \mathrm{Cl} 1.19$ to 6.81 ) for fathers without the habit of smoking.

Conclusions: Paternal smoking behaviour may play an interactive role with HSR in preventing smoking initiation among Taiwanese adolescents.

\section{INTRODUCTION}

An important objective of health agencies worldwide is to protect children from passive smoking that results from family

\section{Strengths and limitations of this study}

- The effect of home smoking restriction (HSR) on adolescent smoking initiation was modified by paternal smoking but not maternal smoking using in a prospective cohort study. If parental behaviour is inconsistent with the regulation, its control will be ineffective.

- If parental behaviour is inconsistent with the regulations, this control will be ineffective.

- In addition to the small sample size that may affect the failure to control for other confounding or to identify other effect modifiers, since the samples were derived from a local city in Taiwan, the results may not be generalised to the whole adolescent population in Taiwan.

- The measurement of HSR and parental smoking were self-reported by the adolescents in the questionnaire.

members smoking in the home. ${ }^{1}$ Thus, the promotion of home-based non-smoking policies is the key to tobacco control programmes because it not only reduces a child's exposure to secondhand smoke but also increases smoking cessation rates. ${ }^{2}$

However, very few Asian countries have reported similar estimates. The National Health Interview Survey (NHIS) of over 20000 Taiwanese in 2001 showed that the prevalence of exposure to environmental tobacco smoke at home (excluding smokers but including occasional exposure) in adolescents aged between 12 and 17 years was $43 \%$ and $42.4 \%$ for boys and girls, respectively, and that the prevalence of exposure to environmental tobacco smoke at home was higher in adolescents than in adults. ${ }^{3}$

The prevalence of smoke-free homes varies but has been increasing over time in countries worldwide. ${ }^{2}$ The prevalence of a strict ban on smoking in the home has increased from $58.1 \%$ in 1995 to $83.8 \%$ in 2007 in the 
USA. ${ }^{4}$ Home smoking restriction (HSR) among US households with children and smokers approximately increased fourfold from $14.1 \%$ in $1992 / 1993$ to $50 \%$ in 2006/2007..$^{5}$ In Finland, 58\% of 12-18-year-old adolescents reported a stark ban non-smoking in their homes. ${ }^{6}$

Several cross-sectional studies found that HSR may reduce teenage smoking, ${ }^{7}$ the likelihood of trying tobacco, ${ }^{89}$ and becoming an ever smoker. ${ }^{10}$ Conversely, a partial ban or the lack of a ban increased the likelihood of being a daily smoker among 12-18-year-olds. ${ }^{6}$

More often than not, parents in most families play a major role in decision-making for their household and set behavioural examples. In Taiwan, Wen $e t a l^{11}$ showed that parental influence was more important than peer influence using a cross-sectional representative sample of 44976 high school students in 1995. Nonetheless, results regarding the effects of parental smoking on HSR and child smoking were discordant. Some researchers have found that HSR reduces the risk of children becoming smokers, even after controlling for parental smoking status. ${ }^{6812}$ Some studies found that adolescent smoking was inversely related to the presence of a restrictive household policy, but the association was attenuated when parental smoking was considered in the model. ${ }^{13}$ Proescholdbell's study showed that although restrictive home smoking policies were associated with a lower likelihood of trying smoking for both middle and high school students, the relation was restricted to homes with non-smoking parents for high school students. ${ }^{8}$ A prospective cohort study, using environmental tobacco smoke exposure at home but not HSR as an indicator, found that higher exposure to secondhand smoke at home predicted the smoking initiation of young Chinese children, independent of parental smoking status. ${ }^{14}$ However, the effect of HSR on smoking among adolescents has not yet been elucidated using a prospective cohort study.

Seventh graders were in the transforming period from primary school to junior middle school. They are sensitive to behaviour change and may try smoking to join in a new group and be identified by the others. ${ }^{15-17}$ It is therefore imperative to understand the effect of HSR on adolescent smoking behaviour.

Generally speaking, though most studies have shown an association between HSR and reduced adolescent smoking behaviours, ${ }^{18}$ it is worthwhile to further investigate a novel postulate regarding the interaction between parental smoking and HSR in association with in a prospective cohort study. By collecting 1-year follow-up school-based data from Taiwanese adolescents, the purposes of this study were: (1) to describe the rate of HSR and who implemented HSR in the families of seventh graders; (2) to describe the relations between parental smoking and HSR among seventh graders; (3) to assess the effect of HSR on smoking initiation among seventh grade never smokers; and (4) to assess the modified effect of parental smoking on the relation between HSR and adolescent smoking initiation.

\section{METHODS}

\section{Study design and participants}

An adolescent cohort study entitled as 'Adolescent smoking and related behaviour survey' was conducted by Keelung City Health Bureau and Chung-Shang Medical University in 2008 based on study participants enrolled from the first-year (seventh grade) students of junior high school. There are 18 junior high schools, 495 classes and 16439 students in Keelung City. We used a simple random sampling method to choose 73 classes of seventh graders with 2446 students. Of 2446 students enrolled in 2008, 1723 responded to the questionnaire (a $70.44 \%$ response rate). To describe the rate of HSR in seventh grade students, we used the data of 1723 seventh grade students. Using the same procedures, a follow-up survey was conducted in October of 2009. Among the 1723 respondents in 2008, 1017 students provided informed consent and participated in the second questionnaire (the follow-up rate was 59.02\%). To assess the effect of HSR on the initiation of smoking, we used the data of 1017 students in eighth grade. After excluding 57 ever smokers at baseline and 59 students who did not provide their smoking status, the remaining 901 without smoking in 2008 were followed in 2009 to ascertain the status of smoking.

The reasons for not participating included lack of parental or individual consent and absence from school on the day of the survey in 2008. Since we had no information on the smoking behaviour of their parents and other factors from the students who did not participate, we were unable to assess whether there were differences between those students who responded and those who did not.

In 2009, as H1N1 (Influenza A virus subtype H1N1) was rampant in Taiwan, there were more students who were absent from class due to the epidemic. The reasons for non-response included lack of consent from the parents and, to a large extent, absence from class due to sickness and, to a lesser extent, the refusal from students themselves. However, there were no differences between the followed-up students $(\mathrm{n}=1017)$ and those lost-to-follow-up $(\mathrm{n}=706)$ with respect to most variables including smoking behaviour $\left(\chi_{(\mathrm{df}=1)}^{2}=3.08, \mathrm{p}=0.0795\right)$, sex $\left(\chi_{(\mathrm{df}=1)}^{2}=0.0006\right.$, $\mathrm{p}=0.9800)$, single family $\left(\chi_{(\mathrm{df}=1)}^{2}=0.70, \mathrm{p}=0.4034\right)$, highest parental education $\left(\chi_{(\mathrm{df}=2)}^{2}=3.57, \mathrm{p}=0.1675\right)$, paternal smoking $\quad\left(\chi_{(\mathrm{df}=1)}^{2}=0.02, \quad \mathrm{p}=0.8908\right)$, maternal smoking $\left(\chi_{(\mathrm{df}=1)}^{2}=2.17, \mathrm{p}=0.1404\right)$, and intention to smoke in the future $\left(\chi_{(\mathrm{df}=1)}^{2}=0.13, \mathrm{p}=0.7177\right)$. Only having a best friend who smoked was significantly different between the two groups $\left(\chi_{(\mathrm{df}=1)}^{2}=4.59, \mathrm{p}=0.0322\right)$, with higher rates of having a best friend that smoked $(11.31 \%)$ among those who were lost to follow-up than those who were followed for the entire study $(8.17 \%)$.

\section{Data collection}

This study utilised a self-administered questionnaire to collect data, which were taken by the students themselves in the classroom. In 2008, the data collection 
procedures included three steps. First, we contacted the school administrators and teachers. The second step was to obtain consent from the students and their parents. All students who provided parental and individual informed consent were included in the study. Finally, trained interviewers collected data from the classes after explaining the purpose of the study and reiterating the ethical issues associated with this research.

\section{Measurement of variables}

The independent variable was smoking initiation that was measured by asking students who had never smoked at 2008, of the question- "Have you ever smoked or made attempt to smoke cigarette"-and with a binary answer (yes/no) at the 2009 follow-up.

All independent variables were collected from the baseline questionnaire at the entry of study in 2008. The main independent variable, HSR, was based on students' selfreported information on whether the definite inhibition of smoking at home or not was stipulated and implemented. Parental smoking behaviour was also reported by students in a similar manner with the question "Did your father/mother smoke in the preceding year?"

Furthermore, we collected information about the person who made the decision about HSR in a multiple selection question. Then we organised the data into four categories as follows: father only, mother only, both father and mother and collective decision made by parents and other members (such as grandparents).

Additional explanatory variables included in the following regression model, which were also collected from the 2008 baseline questionnaire, included sex (boy/girl), highest parental education (junior high school/senior high school/college or university), having a best friend who smoked (yes/no), and intention to smoke in the future (yes/no). The latter two variables were measured by asking the two questions: "Did your best friend have smoked?" and "Have you ever considered making attempt at smoking?"

The contents validity of the questionnaire was based on the literature and was assessed by an expert committee panel.

\section{Statistical analysis}

Frequency and percentage were used to describe the distribution of HSR and smoking initiation stratified by parental smoking behaviour. We used $\chi^{2}$ tests to examine the differences between HSR and smoking initiation. We then applied a Breslow-Day homogeneity test to assess whether the relations between HSR and smoking initiation were modified by parental smoking behaviours. Finally, the logistic regression model was adopted to estimate the effect of HSR on smoking initiation and to assess the interaction between parental smoking and HSR behaviours in association with smoking initiation after adjusting for other extraneous variables.

In the multivariable logistic regression analysis, we used the missing indicator method to take missing values into account to justify the comparison of different models, particularly when a multivariable regression model was conducted. The majority of variables with missing data are less than $5 \%$ except intention to smoke in the future (missing rate $=6.1 \%$ ). It would not affect the results if data analysis is performed with missing completely at random (MCAR) assumption.

A significance level of 5\% was set for assessing statistical significance. All analyses were conducted using SAS V.9.2.

\section{RESULTS}

The rate of HSR and the frequencies of correlates associated with HSR

Among the 1723 seventh grade students, the rate of selfreported HSR was $29.8 \%$. The distributions of the factors associated with HSR are specified in table 1. In the simple logistic regression model, paternal smoking, maternal smoking and highest level of parental education were significantly related to HSR. In the multivariate model, after adjusting for paternal smoking, maternal smoking and highest level of parental education, the rates of HSR among households with paternal and maternal smokers were 2.50 and 1.84 times higher than those without parental smoking, respectively.

\section{The impact of HSR and PSB on smoking initiation}

The relations between HSR or PSB and smoking initiation are shown in table 2. Of the 901 adolescents who were non-smokers at baseline (2008), frequencies $(11.1 \%)$ who may start smoking during the first year of follow-up (during theseventh grade) were ascertained at the second survey in 2009.

Smoking initiation rates were $12.6 \%$ for non-HSR households and $7.6 \%$ for HSR households. Adolescents who lived in homes without HSR were 1.75 times $(95 \%$ CI (1.04 to 2.92)) more likely to initiate smoking compared to those with HSR $\left(\chi_{(\mathrm{df}=1)}^{2}=4.61, \mathrm{p}=0.03\right)$. Smokinginitiating rates were $26.55 \%$ for children of mothers who smoked and $8.48 \%$ for children of mothers who did not smoke. This difference was highly statistically significant $\left(\chi_{(\mathrm{df}=1)}^{2}=33.24, \mathrm{p}<0.001\right)$. Children of mothers who smoked were four times (OR=3.98, 95\% CI (2.44 to 6.51$)$ ) more likely to initiate smoking than children of mothers who did not smoke. In contrast, the father's smoking behaviour was not associated with smoking initiation $\left(\chi_{(\mathrm{df}=1)}^{2}=2.0\right.$, $\mathrm{p}=0.16)$.

The proportion of households with an HSR $(n=504)$ categorised by the decisionmaker was as follows: $11.90 \%$ father only, $27.78 \%$ mother only, $11.51 \%$ both father and mother, $39.09 \%$ collective decision including parents and $9.72 \%$ collective decision excluding parents. Among the 504 households, 272 never smoker households were followed to analyse the relationships between the decisionmaker of the HSR and adolescent-smoking initiation. There was an insignificant relationship between the decision-maker of the HSR and smoking initiation $\left(\chi_{(\mathrm{df}=4)}^{2}=0.69, \mathrm{p}=0.9530\right)$. 
Table 1 Distribution and logistic regression results of parental smoking on home smoking restriction. $(n=1723)$

\begin{tabular}{|c|c|c|c|c|c|c|c|c|c|c|}
\hline \multirow[b]{3}{*}{ Variables } & \multirow[b]{3}{*}{ Number } & \multirow[b]{3}{*}{$\begin{array}{l}\text { Per } \\
\text { cent }\end{array}$} & \multicolumn{5}{|c|}{ Home smoking restriction } & \multirow[b]{3}{*}{$\chi^{2}$ test } & \multicolumn{2}{|l|}{ Logistic regression } \\
\hline & & & \multirow[b]{2}{*}{ NK } & \multicolumn{2}{|l|}{ No } & \multicolumn{2}{|l|}{ Yes } & & \multirow{2}{*}{$\begin{array}{l}\text { Univariate } \\
\text { OR (95\% Cl) }\end{array}$} & \multirow{2}{*}{$\begin{array}{l}\text { Multivariate } \\
\text { OR (95\% Cl) }\end{array}$} \\
\hline & & & & Number & $\begin{array}{l}\text { Per } \\
\text { cent }\end{array}$ & Number & $\begin{array}{l}\text { Per } \\
\text { cent }\end{array}$ & & & \\
\hline & 1723 & & 31 & 1188 & 70.21 & 504 & 29.79 & & & \\
\hline \multicolumn{11}{|l|}{ Paternal smoking } \\
\hline No & 684 & 41.66 & 12 & 388 & 57.74 & 284 & 42.26 & $\chi_{(\mathrm{df}=1)}^{2}=85.73$ & 2.77 (2.22 to 3.45$)$ & 2.50 (1.99 to 3.13$)$ \\
\hline Yes & 958 & 55.60 & 11 & 749 & 79.09 & 198 & 20.91 & $p<0.0001$ & 1 & 1 \\
\hline NK & 81 & & 8 & 51 & & 22 & & & & \\
\hline \multicolumn{11}{|l|}{ Maternal smoking } \\
\hline No & 1389 & 84.34 & 18 & 928 & 67.69 & 443 & 32.31 & $\chi_{(\mathrm{df}=1)}^{2}=21.44$ & 2.21 (1.57 to 3.11$)$ & 1.84 (1.28 to 2.64$)$ \\
\hline Yes & 258 & 15.66 & 5 & 208 & 82.21 & 45 & 17.79 & $\mathrm{p}=0.0005$ & 1 & 1 \\
\hline NK & 76 & & 8 & 52 & & 16 & & & & \\
\hline \multicolumn{11}{|l|}{ Paternal highest education } \\
\hline Junior high school and below & 185 & 10.84 & 6 & 137 & 76.54 & 42 & 23.46 & $\chi_{(\mathrm{df}=2)}^{2}=10.47$ & 1 & 1 \\
\hline Senior high school & 723 & 42.36 & 12 & 515 & 72.43 & 196 & 27.57 & $p=0.0053$ & 1.24 (0.85 to 1.82$)$ & $1.26(0.83$ to 1.91$)$ \\
\hline College or university & 799 & 46.81 & 13 & 522 & 66.41 & 264 & 33.59 & & 1.65 (1.13 to 2.40$)$ & 1.36 (0.90 to 2.06$)$ \\
\hline NK & 16 & & 0 & 14 & & 2 & & & & \\
\hline \multicolumn{11}{|l|}{ Single family } \\
\hline No & 1426 & 84.13 & 23 & 974 & 69.42 & 429 & 30.58 & $\chi_{(\mathrm{df}=1)}^{2}=1.57$ & 1 & - \\
\hline Yes & 269 & 15.87 & 7 & 192 & 73.28 & 70 & 26.72 & $p=0.2106$ & $0.83(0.62$ to 1.11$)$ & \\
\hline NK & 28 & & 1 & 22 & & 5 & & & & \\
\hline \multicolumn{11}{|l|}{ Gender } \\
\hline Girl & 823 & 49.52 & 11 & 571 & 70.32 & 241 & 29.68 & $\chi_{(\mathrm{df}=1)}^{2}=0.0157$ & 1 & - \\
\hline Boy & 839 & 50.48 & 18 & 575 & 70.04 & 246 & 29.96 & $p=0.9003$ & $1.01(0.82$ to 1.25$)$ & \\
\hline NK & 61 & & 2 & 42 & & 17 & & & & \\
\hline \multicolumn{11}{|l|}{ Smoking behaviour } \\
\hline Never & 1506 & 93.14 & 20 & 1028 & 69.18 & 458 & 30.82 & $\chi_{(\mathrm{df}=1)}^{2}=10.64$ & 1 & - \\
\hline Ever & 111 & 6.86 & 4 & 90 & 84.11 & 17 & 15.89 & $\mathrm{p}=0.0011$ & 2.36 (1.39 to 4.01$)$ & \\
\hline NK & 106 & & 7 & 70 & & 29 & & & & \\
\hline
\end{tabular}

\section{The effect modification of PSB}

Whether PSB modified the effect of HSR on smoking initiation in adolescents is specified in table 3 by the stratification of PSB with the application of the Breslow-Day homogeneity test across the estimated ORs. The influence of HSR on smoking initiation was modified by the father's smoking habits $\quad\left(\chi_{(\mathrm{df}=1)}^{2}=3.94\right.$, $\mathrm{p}=0.05)$, but not by the mother's smoking habits $\left(\chi_{(\mathrm{df}=1)}^{2}=0.01, \mathrm{p}=0.92\right)$.

The effect of HSR on smoking initiation among the stratum of parental smoking was small $(\mathrm{OR}=1.09,95 \%$ CI (0.55 to 2.13), $\left.\chi_{(\mathrm{df}=1)}^{2}=0.06, \mathrm{p}=0.81\right)$, but smoking initiation was 3.36 times (95\% CI 1.35 to 8.35 ) higher in adolescents who lived without HSR as compared to those who lived with HSR among that of fathers without smoking. This result shows that paternal smoking modified the effect of HSR on smoking initiation. This interaction effect was also confirmed by the likelihood test $\left(\chi^{2}=3.98, p=0.0460\right)$.

The relationship between smoking initiation and other extraneous variables is shown in table 3. Being male, having a parent who only completed junior high school, being from a single-parent family, having a best friend who smoked and having an intention to smoke in the future indicated a greater likelihood of smoking than being a girl, having a parent who completed college/university education, not being from a singleparent family, having a non-smoking best friend and having no intention of smoking in the future. These variables were controlled in the following multivariable logistic regression models.

The results of the multiple logistic regressions confirmed such a significant interaction between paternal smoking and HSR (as shown by model 1 in table 4) after adjusting for other extraneous variables, but such an interaction was not observed for maternal smoking and HSR (as shown in model 2 of table 4). HSR was a statistically significant influence on smoking initiation among those whose fathers did not smoke (as shown in the paternal non-smoking model in table 5), but this effect was not present among those whose fathers smoke (as shown by the paternal smoking model in table 5), consistent with the results shown in table 3. Among those whose fathers did not smoke, adolescents in families without HSR were more likely to begin smoking than those who lived in HSR families $(\mathrm{OR}=2.84,95 \%$ CI 1.19 to 6.81$)$.

\section{DISCUSSION}

On the basis of the junior high school longitudinal follow-up data, the overall proportion of HSR was $29.79 \%$ among seventh grade adolescents. Our results found that it may be the presence of smoking bans in homes with non-smoking fathers that has a protective effect on smoking initiation. We also confirmed a significant effect of smoking bans in homes on the initiation of smoking in adolescents after controlling for other 
Table 2 Distribution of main variables according to smoking initiation. $(n=901)$

\begin{tabular}{|c|c|c|c|c|c|c|c|c|}
\hline \multirow[b]{3}{*}{ Variables } & \multirow[b]{3}{*}{ Number } & \multirow[b]{3}{*}{ Per cent } & \multicolumn{4}{|c|}{ Smoking initiation } & \multicolumn{2}{|l|}{$\chi^{2}$ test } \\
\hline & & & \multicolumn{2}{|c|}{ No } & \multicolumn{2}{|l|}{ Yes } & \multirow[b]{2}{*}{$\chi^{2}$} & \multirow[b]{2}{*}{$p$ Value } \\
\hline & & & Number & Per cent & Number & Per cent & & \\
\hline Total & 901 & & & & & & & \\
\hline \multicolumn{9}{|c|}{ Home smoking restriction (HSR) } \\
\hline No & 629 & 70.52 & 550 & 87.44 & 79 & 12.56 & \multirow[t]{2}{*}{$\chi_{(\mathrm{df}=1)}^{2}=4.61$} & \multirow[t]{2}{*}{$p=0.0317$} \\
\hline Yes & 263 & 29.48 & 243 & 92.40 & 20 & 7.60 & & \\
\hline NK & 9 & & 8 & & 1 & & & \\
\hline \multicolumn{9}{|l|}{ Paternal smoking } \\
\hline No & 368 & 42.99 & 334 & 90.76 & 34 & 9.24 & \multirow{2}{*}{$\chi_{(\mathrm{df}=1)}^{2}=2.00$} & \multirow[t]{2}{*}{$p=0.1569$} \\
\hline Yes & 488 & 57.01 & 428 & 87.70 & 60 & 12.30 & & \\
\hline NK & 45 & & 39 & & 6 & & & \\
\hline \multicolumn{9}{|l|}{ Maternal smoking } \\
\hline No & 755 & 86.98 & 691 & 91.52 & 64 & 8.48 & \multirow{2}{*}{$\chi_{(\mathrm{df}=1)}^{2}=33.24$} & \multirow[t]{2}{*}{$p<0.0001$} \\
\hline Yes & 113 & 13.02 & 83 & 73.45 & 30 & 26.55 & & \\
\hline NK & 33 & & 27 & & 6 & & & \\
\hline \multicolumn{9}{|l|}{ Gender } \\
\hline Girl & 448 & 51.32 & 419 & 93.53 & 29 & 6.47 & \multirow{2}{*}{$\chi_{(\mathrm{df}=1)}^{2}=20.04$} & \multirow[t]{2}{*}{$p<0.0001$} \\
\hline Boy & 425 & 48.68 & 357 & 84.00 & 68 & 16.00 & & \\
\hline NK & 28 & & 25 & & 3 & & & \\
\hline \multicolumn{9}{|l|}{ Paternal highest education } \\
\hline Junior high school and below & 91 & 10.22 & 74 & 81.32 & 17 & 18.68 & \multirow[t]{4}{*}{$\chi_{(\mathrm{df}=2)}^{2}=6.70$} & \multirow[t]{3}{*}{$p=0.0350$} \\
\hline Senior high school & 391 & 43.93 & 355 & 90.79 & 36 & 9.21 & & \\
\hline College or university & 408 & 45.84 & 361 & 88.48 & 47 & 11.52 & & \\
\hline NK & 11 & & 11 & & 0 & & & \\
\hline \multicolumn{9}{|l|}{ Single family } \\
\hline No & 752 & 84.59 & 683 & 90.82 & 69 & 9.18 & \multirow[t]{2}{*}{$\chi_{(\mathrm{df}=1)}^{2}=18.95$} & $\mathrm{p}<0.0001$ \\
\hline Yes & 137 & 15.41 & 107 & 78.10 & 30 & 21.90 & & \\
\hline NK & 12 & & 11 & & 1 & & & \\
\hline Friend smoking & & & & & & & & \\
\hline No & 805 & 93.71 & 726 & 90.19 & 79 & 9.81 & $\chi_{(\mathrm{df}=1)}^{2}=27.95$ & $p<0.0001$ \\
\hline Yes & 54 & 6.29 & 36 & 66.67 & 18 & 33.33 & & \\
\hline NK & 42 & & 39 & & 3 & & & \\
\hline Intention to smoke & & & & & & & & \\
\hline No & 785 & 92.79 & 724 & 92.23 & 61 & 7.77 & $\chi_{(\mathrm{df}=1)}^{2}=101.11$ & $p<0.0001$ \\
\hline Yes & 61 & 7.21 & 31 & 50.82 & 30 & 49.18 & & \\
\hline NK & 55 & & 46 & & 9 & & & \\
\hline
\end{tabular}

possible causative factors in Taiwanese adolescents. The most novel finding of our study is that the effect of HSR on the start of smoking is modified by parental smoking (eg, the interaction between parental smoking and HSR). Accordingly, by stratifying paternal smoking habits, the effect of HSR on the start of smoking was statistically significant in the absence of paternal smoking, but not in the presence of paternal smoking. However, this effect modification was not noted for maternal smoking.

In spite of several previous relevant studies, the effect of HSR on the initiation of smoking among adolescents has not yet been studied using longitudinal follow-up studies in Taiwan. Therefore, the first aim of this study was to determine the prevalence of HSR. Our study found that the rate of HSR was $29.79 \%$ (95\% CI 27.59 to 31.99) among the families of seventh junior high school adolescents. In general, the total rate of smokefree homes varies from country to country.
In addition to the disparity in the rate of HSR that varies from country to country, the effect of HSR on adolescent smoking has also been inconsistent among previous studies. Many studies have shown that HSR affects adolescent smoking initiation, ${ }^{19}$ daily smoking ${ }^{6}$ or experimental smoking, ${ }^{6} 89$ even after adjusting for parental smoking. However, other studies have shown that HSR has no significant effects on current adolescent smoking behaviour after adjustment for parental smoking. ${ }^{8913}$

From the perspective of social behaviour science, HSR affects adolescent smoking initiation in several ways. First, HSR builds a smoke-free supportive physical environment ${ }^{9} 12$ that provides a smoke-free subjective norm and attitude ${ }^{19}$ and exerts parental control over adolescents. ${ }^{20}$ Second, the adoption of HSR may have spillover effects, which are supported by the fact that forbidding smoking indoors is associated with having fewer peers who smoke. This spillover effect offers some preliminary ideas regarding why home indoor 
Table 3 The effect of smoking ban at home and initiation of smoking among eighth grade students stratified by parental smoking behaviour. ( $\mathrm{N}=901)$

\begin{tabular}{|c|c|c|c|c|c|c|c|c|c|c|}
\hline \multirow[b]{3}{*}{$\begin{array}{l}\text { Stratified } \\
\text { variables }\end{array}$} & \multirow[b]{3}{*}{ Number } & \multirow[b]{3}{*}{$\begin{array}{l}\text { Per } \\
\text { cent }\end{array}$} & \multicolumn{8}{|c|}{ Initiation of smoking } \\
\hline & & & \multicolumn{2}{|c|}{ Never smoker } & \multicolumn{2}{|l|}{ Initiator } & \multicolumn{2}{|l|}{$\chi^{2}$ test } & \multicolumn{2}{|l|}{ Logistic regression } \\
\hline & & & Number & $\begin{array}{l}\text { Per } \\
\text { cent }\end{array}$ & Number & $\begin{array}{l}\text { Per } \\
\text { cent }\end{array}$ & $\chi^{2}$ & p Value & OR $(95 \% \mathrm{Cl})$ & p Value \\
\hline \multicolumn{11}{|c|}{ Paternal smoking ${ }^{\star a}$} \\
\hline \multicolumn{11}{|c|}{ Father with smoking $(\mathrm{N}=488)$} \\
\hline \multicolumn{11}{|c|}{ HSR } \\
\hline No & 383 & 78.81 & 335 & 87.47 & 48 & 12.53 & \multirow[t]{2}{*}{$\chi_{(\mathrm{df}=1)}^{2}=0.0584$} & \multirow[t]{2}{*}{$\mathrm{p}=0.8091$} & 1 & \multirow[t]{2}{*}{$\mathrm{p}=0.8091$} \\
\hline Yes & 103 & 21.19 & 91 & 88.35 & 12 & 11.65 & & & 1.09 (0.55 to 2.13$)$ & \\
\hline NK & 2 & & 2 & & 0 & & & & & \\
\hline \multicolumn{11}{|c|}{ Father without smoking $(\mathrm{N}=368)$} \\
\hline HSR & & & & & & & & & & \\
\hline No & 216 & 59.50 & 189 & 87.50 & 27 & 12.50 & \multirow{2}{*}{$\chi_{(\mathrm{df}=1)}^{2}=7.5008$} & \multirow[t]{2}{*}{$p=0.0062$} & 1 & \multirow[t]{2}{*}{$p=0.0092$} \\
\hline Yes & 147 & 40.50 & 141 & 95.92 & 6 & 4.08 & & & 3.36 (1.35 to 8.35$)$ & \\
\hline NK & 5 & & 4 & & 1 & & & & & \\
\hline \multicolumn{11}{|c|}{ Maternal smoking $\dagger$} \\
\hline \multicolumn{11}{|c|}{ Mother with smoking $(\mathrm{N}=113)$} \\
\hline \multicolumn{11}{|c|}{ HSR } \\
\hline No & 94 & 83.93 & 68 & 72.34 & 26 & 27.66 & \multirow[t]{2}{*}{$\chi_{(\mathrm{df}=1)}^{2}=0.2277$} & \multirow[t]{2}{*}{$p=0.6332$} & 1 & \multirow[t]{2}{*}{$p=0.6341$} \\
\hline Yes & 18 & 16.07 & 14 & 77.78 & 4 & 22.22 & & & $1.34(0.41$ to 4.44$)$ & \\
\hline NK & 1 & & 1 & & 0 & & & & & \\
\hline \multicolumn{11}{|c|}{ Mother without smoking $(\mathrm{N}=755)$} \\
\hline \multicolumn{11}{|c|}{ HSR } \\
\hline No & 508 & 67.82 & 461 & 90.75 & 47 & 9.25 & \multirow[t]{3}{*}{$\chi_{(\mathrm{df}=1)}^{2}=1.4487$} & \multirow[t]{3}{*}{$p=0.2287$} & 1 & \multirow[t]{3}{*}{$\mathrm{p}=0.2311$} \\
\hline Yes & 241 & 32.18 & 225 & 93.36 & 16 & 6.64 & & & $1.43(0.80$ to 2.58$)$ & \\
\hline NK & 6 & & 5 & & 1 & & & & & \\
\hline
\end{tabular}

smoking restrictions reduce adolescent smoking. ${ }^{21}$ In general, HSR may represent a contextual factor of a family bond that precludes adolescents and family members from smoking. A previous study conducted on ninth grade students in Taiwan found that strong family relations could be a protective factor against substance use (including smoking). ${ }^{22}$ HSR may also represent one of the strategies for monitoring the health behaviour of adolescents to prevent them from developing unhealthy behaviours. ${ }^{23}$ The strongest effect on youth smoking is parental smoking and the role of home smoking bans seems to be modified by paternal smoking. This finding may account for the fact why some studies found an effect and others did not, as the interaction between parental smoking and HSR was not considered.

On the basis of these findings, it is necessary to identify significant correlates (including parental smoking and other significant factors) that account for the underlying contextual factors in relation to HSR strategies.

The effect of HSR on adolescent smoking initiation has been thought to be confounded by other factors.

Table 4 The effect of home smoking restriction on smoking initiation among junior high school students in Taiwan-logistic regression analysis results $(n=901)$

\begin{tabular}{|c|c|c|c|c|c|c|}
\hline \multirow[b]{3}{*}{ Variables at 7 th grade } & \multicolumn{6}{|c|}{$\begin{array}{l}\text { Smoking initiation from } 7 \text { th grade to } 8 \text { th grade among never smoking } \\
\text { students }\end{array}$} \\
\hline & \multicolumn{3}{|c|}{ Model 1} & \multicolumn{3}{|c|}{ Model 2} \\
\hline & Coefficient & (SE) & p Value & Coefficient & (SE) & p Value \\
\hline Home smoking restriction (no/yes) & 1.06 & $(0.44)$ & 0.0160 & 0.36 & $(0.31)$ & 0.2507 \\
\hline Paternal smoking (yes/no) & -0.40 & $(0.28)$ & 0.1470 & -0.13 & $(0.25)$ & 0.6028 \\
\hline Maternal smoking (yes/no) & 1.18 & (0.29) & $<0.0001$ & 1.24 & (0.32) & $<0.0001$ \\
\hline Gender (boy/girl) & 1.02 & $(0.25)$ & $<0.0001$ & 1.04 & $(0.25)$ & $<0.0001$ \\
\hline Family structure (single parental/not) & 0.56 & $(0.28)$ & 0.0440 & 0.58 & $(0.28)$ & 0.0376 \\
\hline Parental highest education (SHS/JHS) & -0.66 & (0.35) & 0.0610 & -0.63 & $(0.35)$ & 0.0745 \\
\hline Parental highest education (university/JHS) & -0.35 & (0.35) & 0.3090 & -0.33 & $(0.35)$ & 0.3392 \\
\hline Friend smoking (yes/no) & 0.83 & $(0.37)$ & 0.0240 & 0.84 & $(0.37)$ & 0.0239 \\
\hline Future smoking intention (yes/no) & 1.97 & (0.32) & $<0.0001$ & 1.94 & (0.32) & $<0.0001$ \\
\hline Interaction: paternal smoking×HSR & 1.18 & $(0.58)$ & 0.0410 & & & \\
\hline Interaction: maternal smoking $\times$ HSR & & & & -0.46 & $(0.75)$ & 0.5395 \\
\hline
\end{tabular}


Table 5 The effect of home smoking restriction on smoking initiation among junior high school students in Taiwan by the status of paternal smoking $(n=901)$

\begin{tabular}{|c|c|c|c|c|c|c|}
\hline \multirow[b]{3}{*}{ Variables at 7 th grade } & \multicolumn{6}{|c|}{$\begin{array}{l}\text { Smoking initiation from } 7 \text { th grade to } 8 \text { th grade among never smoking } \\
\text { students }\end{array}$} \\
\hline & \multicolumn{3}{|c|}{ Paternal smoking model $(n=488)$} & \multicolumn{3}{|c|}{$\begin{array}{l}\text { Paternal non-smoking model } \\
(n=413)\end{array}$} \\
\hline & OR & $(95 \% \mathrm{Cl})$ & p Value & OR & $(95 \% \mathrm{Cl})$ & p Value \\
\hline Home smoking restriction (no/yes) & 0.89 & $(0.421 .88)$ & 0.7584 & 2.84 & $(1.196 .81)$ & 0.0191 \\
\hline Maternal smoking (yes/no) & 2.79 & (1.42 5.52) & 0.0031 & 4.86 & (1.62 14.60) & 0.0049 \\
\hline Gender (boy/girl) & 2.77 & (1.44 5.31) & 0.0022 & 2.55 & $(1.195 .45)$ & 0.0160 \\
\hline Family structure (single parental/not) & 2.12 & (1.06 4.25) & 0.0333 & 1.18 & $(0.433 .21)$ & 0.7450 \\
\hline Parental highest education (SHS/JHS) & 0.53 & $(0.211 .35)$ & 0.1851 & 0.44 & (0.15 1.26) & 0.1255 \\
\hline Parental highest education (university/JHS) & 0.84 & (0.34 2.09) & 0.7147 & 0.55 & $(0.201 .54)$ & 0.2556 \\
\hline Friend smoking (yes/no) & 1.74 & (0.69 4.38) & 0.2406 & 3.64 & (1.05 12.67) & 0.0419 \\
\hline Future smoking intention (yes/no) & 9.66 & (4.31 21.62) & $<0.0001$ & 5.59 & (1.78 17.54) & 0.0032 \\
\hline
\end{tabular}

Though household smoking restrictions offer health benefits, they do not appear to be associated with adolescent smoking after accounting for other factors. ${ }^{13}$ Different reasons for HSR implementation may lead to different findings. For example, families reported that they would consider a total ban to protect children from secondhand smoke and to protect family members if they became sick. ${ }^{24}$

In our study, it is interesting to note that paternal, but not maternal, smoking modified the effect of HSR on smoking initiation. It is also important to note that most of the previous studies treated parental smoking as a single dichotomous variable (yes/no ${ }^{25}$ or assigned smoking status to three categories (none, one, or two parents smoke), ${ }^{26}$ but few studies treated parental smoking behaviour as two independent variables, paternal smoking and maternal smoking. This may partially account for why the relationships between parental smoking and adolescent smoking behaviour were inconsistent. ${ }^{27}$ The modified effect of paternal, but not maternal, smoking is supported by two postulates. First, the traditional patriarchal society allows paternal behaviour to have a greater influence on both the regulations at home and the effect of these regulations on adolescents. Second, regulations at home are often not concordant with paternal behaviour. In the case of paternal smoking and HSR, teaching by personal example has more power to change behaviours than verbal instructions. The latter two points make a large contribution to explaining why paternal smoking has the most influence on the initiation of smoking in adolescents.

According to the rates and ORs of paternal and maternal smoking behaviour on HSR, we found that the rate of HSR in the paternal smoking families was higher than that in maternal smoking families. Prior studies have shown similar results ${ }^{6}$ However, another study showed contradictory results. ${ }^{13}$ The explanations and mechanisms for this association require further investigation.
Regarding the factors associated with smoking initiation and paternal smoking, the influence of best friend smoking on the start of smoking differed according to paternal smoking habits. In the families where the father smoked, having a best friend who smoked did not have a significant influence on the initiation of smoking. However, in families where the father did not smoke, as observed in previous studies, ${ }^{28}$ adolescents with best friends who smoked were more likely to begin smoking when other factors were controlled for. This result seems to imply that the effect of paternal smoking on smoking initiation was stronger than best friend smoking because the latter's influence was only observed in situations where the father did not smoke. This phenomenon may occur because parents influence their children's decision to select smoking friends through their own smoking behaviour and their parenting styles. ${ }^{28}$

According to our findings, the smoke-free places policy should consider including households. It is very sensitive to demarcate the boundary between the 'private' home and public health interventions. Though expert panels in the UK concluded that there was a lack of evidence on the relative effectiveness of specific community approaches to increasing restrictions on smoking in the home, ${ }^{29}$ some countries still tried to develop interventions or strategies to promote families' HSR. ${ }^{29} 30$ On the other hand, to prevent children from smoking as well as the harm of secondhand smoking exposure, parents and other family members should quit smoking or at least reduce smoking at home. ${ }^{14}$

\section{Study limitation}

There are some limitations to this study. First, owing to the low follow-up rate $(59 \%$, lost 706 participants) and information regarding the smoking status being absent from one of the two questionnaires (lost 116 participants), only 901 participants were analysed. Therefore, the small sample size used to evaluate smoking initiation $(\mathrm{n}=100)$ may not be sufficient to observe a statistically 
significant difference. We believe that the reasons for loss to follow-up was non-differential as there is a lack of apparent causes related to smoking status. Second, the measurement of HSR and parental smoking were selfreported by the adolescents in the questionnaire. Since the purpose of this study was to investigate the effect of HSR on adolescent smoking initiation, adolescents' perception of HSR may be more important than actuality. Finally, since we did not collect data on the smoking status of other adults living in the same family, we could not know other smokers in the household and failed to assess if this had any impact on the results. However, in Keelung city, multifamily households are few. ${ }^{31}$

\section{Implication for health policy}

Policies regarding smoke-free spaces should be considered at the household level. In this study, we were aware of the sensitivities around the boundary between the 'private' home and public health interventions. Some countries have tried to develop interventions or strategies to promote the implementation of HSR in the home. ${ }^{30}$ Furthermore, just as Farkas (2000) reiterated the importance of tobacco control strategies targeting the entire population rather than youth alone, parents and other family members should quit smoking or at least reduce smoking in the home. ${ }^{12}$

\section{Author affiliations}

${ }^{1}$ School of Public Health, Chung Shan Medical University, Taichung, Taiwan

${ }^{2}$ Department of Family and Community Medicine, Chung Shan Medical University Hospital, Taichung, Taiwan

${ }^{3}$ Graduate Institute of Epidemiology and Preventive Medicine, College of Public Health, National Taiwan University, Taipei, Taiwan

${ }^{4}$ School of Oral Hygiene, College of Oral Medicine, Taipei Medical University, Taipei, Taiwan

${ }^{5}$ Department and Graduate Institute of Health Care Management, Chang Gung University, Taoyuan, Taiwan

${ }^{6}$ Department of Health Industry Management, School of Healthcare

Management, Kainan University, Taoyuan, Taiwan

Acknowledgements The manuscript has been edited by highly qualified native English speakers at American Journal Experts (AJE).

Contributors D-LL and $\mathrm{H}-\mathrm{HC}$ have full access to the data and take responsibility for the integrity of the data and the accuracy of the data analysis. D-LL, T-TW and H-HC contributed by taking part in study concept and design. D-LL, T-TW, SY-HC and H-HC contributed by taking part in acquisition of data. D-LL, T-TW and $\mathrm{H}-\mathrm{HC}$ were involved in drafting of the manuscript. D-LL, T-TW, SL-SC, AM-FY, SY-HC, C-YF and H-HC were involved in critical revision of the manuscript for important intellectual content. D-LL, SL-SC, AM-FY, SY-HC and H-HC were involved in statistical analysis. D-LL and T-TW obtained funding. D-LL, T-TW, SL-SC, AM-FY, SY-HC, C-YF and H-HC contributed by taking part in administrative, technical or material support. D-LL and $\mathrm{H}-\mathrm{HC}$ had the final responsibility for the decision to submit for publication.

Funding This study was funded by the Keelung City Health Bureau.

Competing interests None declared

Ethics approval This project was approved by the Internal Review Board of the Taipei Medical University in Taiwan (approval number:201112040).

Provenance and peer review Not commissioned; externally peer reviewed.

Data sharing statement No additional data are available.
Open Access This is an Open Access article distributed in accordance with the Creative Commons Attribution Non Commercial (CC BY-NC 4.0) license, which permits others to distribute, remix, adapt, build upon this work noncommercially, and license their derivative works on different terms, provided the original work is properly cited and the use is non-commercial. See: http:// creativecommons.org/licenses/by-nc/4.0/

\section{REFERENCES}

1. Robinson J, Ritchie D, Amos A, et al. Volunteered, negotiated, enforced: family politics and the regulation of home smoking. Sociol Health IIIn 2011;33:66-80.

2. Mills AL, Messer K, Gilpin EA, et al. The effect of smoke-free homes on adult smoking behavior: a review. Nicotine Tob Res 2009;11:1131-41.

3. Wen CP, Levy DT, Cheng TY, et al. Smoking behaviour in Taiwan, 2001. Tob Control 2012;14(suppl 1):i51-5.

4. Zhang $X$, Martinez-Donate AP, Kuo D, et al. Trends in home smoking bans in the U.S.A., 1995-2007: prevalence, discrepancies and disparities. Tob Control 2012;21:330-6.

5. Mills AL, White MM, Pierce JP, et al. Home smoking bans among U. S. households with children and smokers. Opportunities for intervention. Am J Prev Med 2011;41:559-65.

6. Rainio SU, Rimpela $\mathrm{AH}$. Home smoking bans in Finland and the association with child smoking. Eur J Public Health 2008;18:306-11.

7. Wakefield MA, Chaloupka FJ, Kaufman NJ, et al. Effect of restrictions on smoking at home, at school, and in public places on teenage smoking: cross sectional study. BMJ 2000;321:333-7.

8. Proescholdbell RJ, Chassin L, MacKinnon DP. Home smoking restrictions and adolescent smoking. Nicotine Tob Res 2000;2:159-67.

9. Szabo E, White V, Hayman J. Can home smoking restrictions influence adolescents' smoking behaviors if their parents and friends smoke? Addict Behav 2006;31:2298-303.

10. Farkas AJ, Gilpin EA, White MM, et al. Association between household and workplace smoking restrictions and adolescent smoking. JAMA 2000;284:717-22.

11. Wen CP, Tsai SP, Cheng TY, et al. Role of parents and peers in influencing the smoking status of high school students in Taiwan. Tob Control 2005;14(suppl 1):i10-15.

12. Ditre JW, Coraggio JT, Herzog TA. Associations between parental smoking restrictions and adolescent smoking. Nicotine Tob Res 2008;10:975-83.

13. Fisher LB, Winickoff JP, Camargo CA Jr, et al. Household smoking restrictions and adolescent smoking. Am J Health Promot 2007;22:15-21.

14. Wang MP, Ho SY, Lam TH. Parental smoking, exposure to secondhand smoke at home, and smoking initiation among young children. Nicotine Tob Res 2011;13:827-32.

15. Jessor R. Problem behavior and developmental transition in adolescence. J Sch Health 1982;52:295-300.

16. Christie D, Viner R. Adolescent development. BMJ 2005;330:301-4

17. Mayhew KP, Flay BR, Mott JA. Stages in the development of adolescent smoking. Drug Alcohol Depend 2000;59:61-81.

18. Emory K, Saquib N, Gilpin EA, et al. The association between home smoking restrictions and youth smoking behaviour: a review. Tob Control 2010;19:495-506.

19. Conley Thomson C, Siegel M, Winickoff J, et al. Household smoking bans and adolescents' perceived prevalence of smoking and social acceptability of smoking. Prev Med 2005;41:349-56.

20. den Exter Blokland EA, Hale WW III, Meeus W, et al. Parental support and control and early adolescent smoking: a longitudinal study. Subst Use Misuse 2007;42:2223-32.

21. Rodriguez D, Tscherne J, Audrain-McGovern J. Contextual consistency and adolescent smoking: testing the indirect effect of home indoor smoking restrictions on adolescent smoking through peer smoking. Nicotine Tob Res 2007:9:1155-61.

22. Wu GH, Chong MY, Cheng AT, et al. Correlates of family, school, and peer variables with adolescent substance use in Taiwan. Soc Sci Med 2007:64:2594-600.

23. Veronneau MH, Dishion TJ. Predicting change in early adolescent problem behavior in the middle school years: a mesosystemic perspective on parenting and peer experiences. J Abnorm Child Psychol 2010;38:1125-37.

24. Escoffery C, Kegler MC, Butler S. Formative research on creating smoke-free homes in rural communities. Health Educ Res 2009;24:76-86.

25. Borland $\mathrm{R}$, Yong $\mathrm{HH}$, Cummings $\mathrm{KM}$, et al. Determinants and consequences of smoke-free homes: findings from the International 
Tobacco Control (ITC) Four Country Survey. Tob Control 2006;15 (Suppl 3):iii42-50.

26. Waa A, Edwards R, Newcombe R, et al. Parental behaviours, but not parental smoking, influence current smoking and smoking susceptibility among 14 and 15 year-old children. Aust N Z J Public Health 2011;35:530-6.

27. Garmiene A, Zemaitiene N, Zaborskis A. Family time, parental behaviour model and the initiation of smoking and alcohol use by ten-year-old children: an epidemiological study in Kaunas, Lithuania. BMC Public Health 2006;6:287.

28. McVicar D. Estimates of peer effects in adolescent smoking across twenty six European countries. Soc Sci Med 2011;73:1186-93.
29. Ritchie D, Amos A, Phillips R, et al. Action to achieve smoke-free homes-an exploration of experts' views. BMC Public Health 2009;9:112.

30. Alwan N, Siddiqi K, Thomson H, et al. Can a community-based 'smoke-free homes' intervention persuade families to apply smoking restrictions at homes? J Public Health (Oxf) 2011;33:48-54.

31. Chiu SY, Chen LS, Yen AM, et al. Population-based proband-oriented pedigree information system: application to hypertension with population-based screening data (KCIS No. 25). J Am Med Inform Assoc 2012; 19:102-10. 